
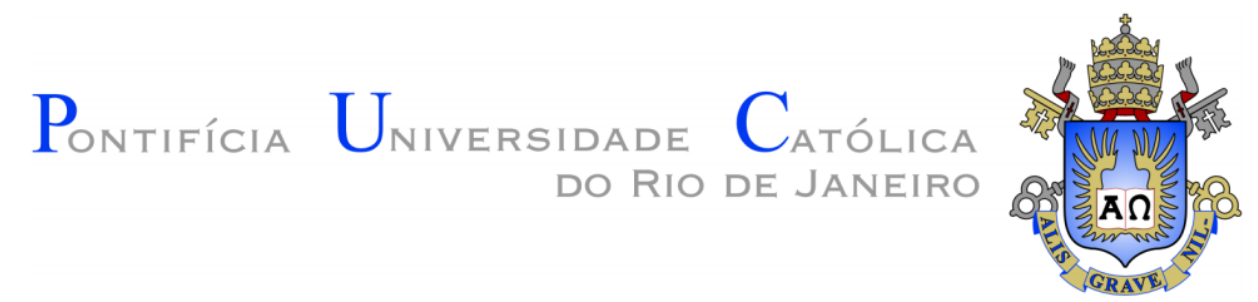

Rodrigo Dietrich

Análise da relação entre as diferentes classes de um voo e o consumo no Free Shop dos aeroportos brasileiros

TRABALHO DE CONCLUSÃO DE CURSO

DEPARTAMENTO DE ADMINISTRAÇÃO

Centro de Ciências Sociais Graduação em Administração de Empresas

Rio de Janeiro, Junho de 2019 


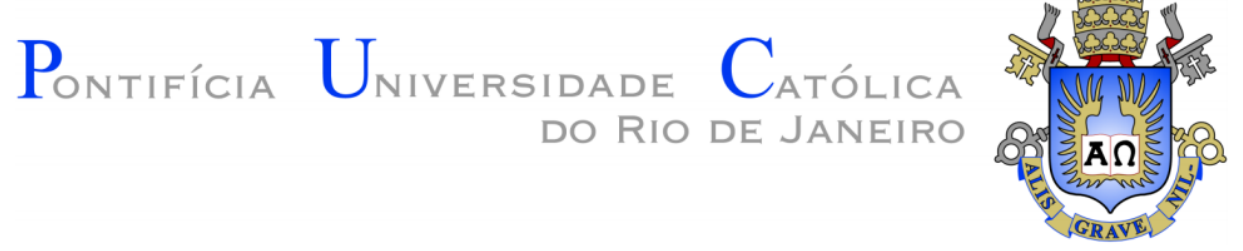

Rodrigo Dietrich

\section{Análise da relação entre as diferentes classes de um voo e o consumo no Free Shop dos aeroportos brasileiros}

\section{Trabalho de Conclusão de Curso}

Trabalho de Conclusão de Curso, apresentado ao programa de graduação em Administração da PUC-Rio como requisito parcial para a obtenção do título de graduação em Administração.

Orientador: Daniel Kamlot 


\section{Agradecimentos}

Gostaria de iniciar agradecendo ao grande apoio recebido dos meus pais e irmão durante estes anos para que eu tivesse toda a estrutura para conseguir me formar.

Aos meus colegas de classe que serão brilhantes administradores por participarem comigo desta jornada incrível.

À minha namorada, por participar de todos os momentos estressantes e exaustivos e permanecer com o apoio de sempre

Ao meu orientador, Daniel Kamlot, por me oferecer o apoio necessário para

a

realização

deste

estudo. 


\section{Resumo}

Dietrich, Rodrigo. Análise da relação entre as diferentes classes de um voo e o consumo no Free Shop dos aeroportos brasileiros. Rio de Janeiro, 2019. 25 p. Trabalho de Conclusão de Curso Departamento de Administração. Pontifícia Universidade Católica do Rio de Janeiro.

Este Trabalho teve como objetivo analisar o comportamento consumidor no Aeroporto internacional do Rio de Janeiro, especificamente em seu terminal de desembarque. O estudo apresentou toda uma base teórica ampla sobre o comportamento do consumidor e seus fatores motivacionais.

O objetivo central se conteve a observar uma possível relação entre o viajante optar por uma diferente classe de voo afetar em seu comportamento de compra na loja Free shop e seus motivos através de uma pesquisa quantitativa.

\section{Palavras-chave}

Comportamento, Consumidor, Varejo, Aeroportos, Compra. 


\section{Abstract}

Dietrich, Rodrigo. Análise da relação entre as diferentes classes de um voo e o consumo no Free Shop dos aeroportos brasileiros. Rio de Janeiro, 2019. 25 p. Trabalho de Conclusão de Curso Departamento de Administração. Pontifícia Universidade Católica do Rio de Janeiro.

This study aimed to analyze consumer behavior at the international airport of Rio de Janeiro, specifically at its landing terminal.

The study presented a broad theoretical basis on consumer behavior and its motivational factors.

The central objective was to observe a possible relationship between the traveler choosing a different class of flight to affect in his shopping behavior in the shop Free shop and his reasons through a quantitative search.

\section{Key-words}

Behavior, Consumer, Retail, Airports, Purchase. 


\section{Lista de Quadros}

Quadro 1: Perfil demográfico..................................................................... 13

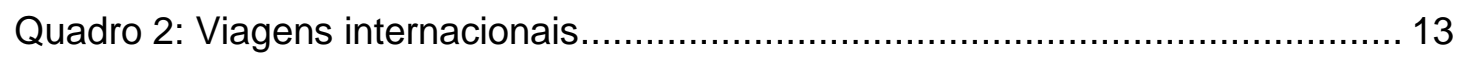

Quadro 3: Gasto médio no Duty Free............................................................ 14

Quadro 4: Relação renda mensal com classe ............................................... 15

Quadro 5: Relação categoria do produto comprado com as classes ....................... 16

Quadro 6: Relação método de pagamento com as classes................................ 17

Quadro 7: Avaliação sobre o ato da compra entre as classes ............................... 18

Quadro 8: Avaliação sobre o ato da compra a ser realizada por o Free Shop apresentar um bom custo benefício entre as classes ........................................... 19

Quatro 9: Avaliação sobre o ato da compra ser realizada por o Free Shop apresentar um ambiente agradável entre as classes ......................................................... 20

Quadro 10: Avaliação sobre o ato da compra ser realizada por o Free Shop apresentar um portfólio exclusivo entre as classes .............................................. 21

Quadro 11: Avaliação sobre o ato da compra ser realizada por o Free Shop apresentar um bom atendimento entre as classes ........................................... 22

Quadro 12: Avaliação sobre o ato da compra ser realizada por o Free Shop apresentar uma experiência diferente entre as classes 22 


\section{Lista de Figuras}

Figura 1: A pirâmide de necessidades de Maslow. 4 


\section{Sumário}

1 Problema de estudo 1

1.1 Introdução ao tema e ao problema do estudo 1

1.2 Objetivo do estudo 2

1.3 Delimitação e foco do estudo 2

1.4 Justificativa e relevância do estudo 3

2 Revisão de literatura 4

2.1 Motivações e desejos dos indivíduos 4

2.2 Processo de decisão de compra 5

$\begin{array}{lll}2.3 & \text { Os diferentes perfis de consumidores } & 7\end{array}$

3 Metodologia 9

$\begin{array}{lll}3.1 & \text { Tipo de pesquisa selecionado } & 9\end{array}$

3.2 Universo e amostra 9

$\begin{array}{lll}3.3 & \text { Coleta de dados } & 10\end{array}$

3.4 Tratamento dos dados 11

3.5 Limitações do método 11

4 Análise dos resultados $\quad 12$

$\begin{array}{lll}4.1 & \text { Perfil da amostra } & 12\end{array}$

$\begin{array}{lll}4.2 & \text { Resultados } & 13\end{array}$

5 Considerações finais 23

6 Referências Bibliográficas 25

7 Apêndice - Questionário aplicado aos consumidores do Free Shop 27 


\section{Problema de estudo}

\subsection{Introdução ao tema e ao problema do estudo}

O trabalho aqui apresentado analisou especificamente aspectos dentro mercado de varejo de viagem. O mesmo pode ser definido como, segundo o Conselho Mundial Duty Free (2019), a venda de produtos para viajantes internacionais por preços mais competitivos devido à isenção de certos impostos locais e nacionais. De acordo com números apresentados pela mesma organização, esta indústria global é responsável por movimentar mais de 680 milhões de dólares no ano de 2017.

Pode-se definir como os espaços que compõem o varejo de viagem: lojas em zonas de embarque e desembarque internacionais em aeroportos, a venda realizada durantes os voos internacionais, cruzeiros em travessias em mares internacionais e lojas em zonas de fronteira. Os mesmos têm se tornado importantes polos comerciais impulsionados pelo aumento constante de viagens internacionais mundialmente e principalmente como espaços extremamente valiosos de exposição da marca (FERREIRA,2012).

Segundos dados estimados pela Tax Free World Association (2019), o tamanho desta indústria e seu aumento ao longo dos últimos anos chega à impressionante marca de uma receita aproximada de quase setenta bilhões de dólares no ano de 2017.

Tratando de abordar mais especificamente o mercado no Brasil, a ANAC (2016) divulgou que, em 2016, foram transportados mais de cem milhões de passageiros no país que pagaram pelo seu transporte, sendo viagens internacionais responsáveis por mais de $20 \%$ deste total. Os quase vinte e um milhões de passageiros em voos internacionais indicam um enorme potencial de consumo em lojas Duty Free. 
Sendo ainda mais focalizado, o Aeroporto internacional Tom Jobim é um dos maiores aeroportos do mundo, possuindo a maior pista de aterrissagem e decolagem do país a e contendo uma das melhores estruturas tecnológicas e logísticas da América do Sul (RIO GALEÃO, 2018). Segundo dados da Rio Galeão (2018), o aeroporto teve fluxo de passageiros em voos internacionais correspondendo a uma média superior a quatro milhões nos anos de 2015 a 2017.Para o ano de 2018, a gestora do aeroporto internacional carioca estimou um aumento total do fluxo de passageiros de $5 \%$.

Toda esta apresentação do mercado a ser analisado nos leva ao questionamento base do trabalho: existe uma relação entre as diferentes classes de um avião em um voo internacional e o consumo dos passageiros nas lojas Free Shop?

\subsection{Objetivo do estudo}

O objetivo deste trabalho será de identificar se há e qual é a relação entre o consumo feito em lojas Free Shop com as diferentes classes de avião dos voos internacionais.

\subsection{Delimitação e foco do estudo}

Devido ao grande número de possibilidades de análises dentro do segmento de varejo de viagem, o trabalho se aterá a especificamente buscar os objetivos previamente mencionados na área de desembarque do Aeroporto Internacional do Rio de Janeiro, correspondendo ao consumo das categorias específicas de: perfumaria, bebidas alcoólicas, comestíveis e bebidas não alcoólicas, eletrônicos, produtos têxteis, joias, relógios e óculos na loja desembarque da empresa Dufry 17. 


\subsection{Justificativa e relevância do estudo}

O objetivo proposto do trabalho aborda a busca de um novo aspecto que seja diretamente relacionado ao comportamento do consumidor nos comércios livres de impostos de importação presentes na grande maioria dos aeroportos internacionais do planeta.

Portanto, nitidamente, será de grande relevância para a vida acadêmica ligada ao estudo do conceito abrangente de comportamento do consumidor buscando identificar novos aspectos que afetam no comportamento de compra dos consumidores.

Além desse grupo, o trabalho trará elementos que colaboram para avanços nas organizações que trabalham diretamente com a indústria de varejo de viagem, visto trazer um maior entendimento dos seus próprios consumidores ou potenciais clientes, podendo adaptar e criar novas estratégias para melhorar o resultado das mesmas.

Por último, o trabalho apresentará um conteúdo muito relevante e agregador para os próprios passageiros internacionais, que poderão ter uma perspectiva nova sobre como seu comportamento de compra é influenciado (ou não) diante de um aspecto distinto para poder avaliar e reconhecer melhor suas compras. 


\section{Revisão de literatura}

\subsection{Motivações e desejos dos indivíduos}

Motivação possui o significado, segundo dicionário da língua brasileira Michaelis (2019), de ser uma série de fatores, de natureza afetiva, intelectual ou fisiológica, que atuam no indivíduo, determinando-Ihe o comportamento.

Uma das teorias mais famosas no âmbito do comportamento do consumidor é a proposta por Maslow (1943), que propôs uma hierarquia de importância entre cinco diferentes necessidades que todos os indivíduos que vivem em uma sociedade possuem: fisiológicas, de segurança, social, de estima e realizações pessoais.

O nível de prioridade do indivíduo perante suas necessidades começa da base mais achatada com suas necessidades fisiológicas e apenas busca atingir sua próxima necessidade, um nível acima, quando esta é completamente satisfeita.

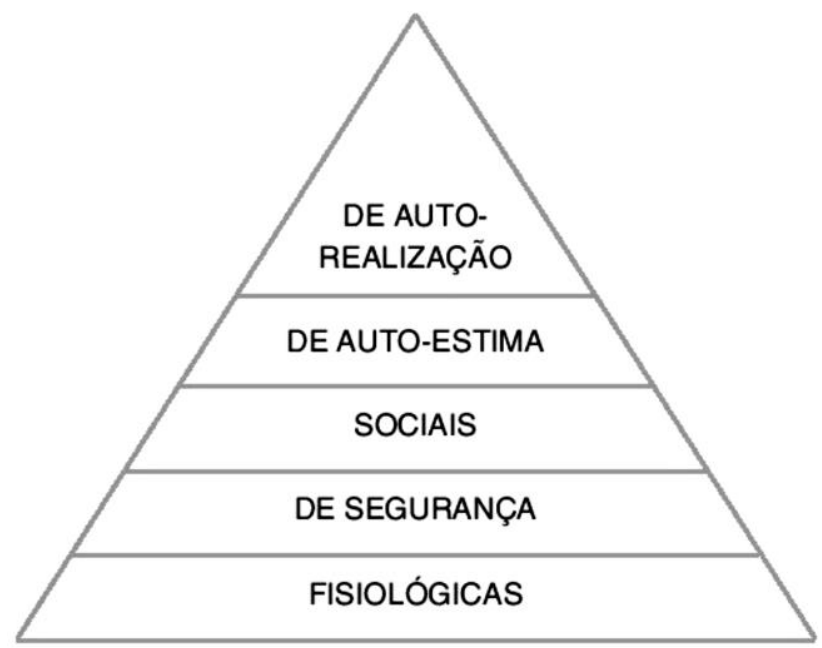

Figura 1: A pirâmide de necessidades de Maslow Fonte: Maslow (1943) 
Segundo Maslow (1943), cada uma das necessidades pode ser definida conforme abaixo:

Necessidades fisiológicas: Fazem parte da biologia dos seres humanos. Necessidades essenciais para a sobrevivência dos mesmos.

Necessidades de Segurança: Fazem parte do que é necessário para a manutenção de uma estabilidade e segurança de cada indivíduo. Sem a sensação de ameaça ou risco.

Necessidades Sociais: Fazem parte do que é necessário para o ser humano se sentir bem perante a sociedade em qual o mesmo habita e se relaciona;

Necessidades de Autoestima: Fazem parte do que é necessário para que a pessoa se sinta valorizada e respeita por demais e por si mesmo perante suas atitudes.

Necessidades de Auto realização: Fazem parte do que todo humano traça como meta de uma vida mais bem-sucedida e satisfatória.

O comportamento do consumidor, segundo Kotler (1996), busca apresentar como as empresas e pessoas se comportam perante o consumo para satisfazer suas necessidades e desejos.

Para Kotler e Keller (2006), a empresa atualmente já tem que estar apta para identificar as necessidades dos clientes, através do estudo de comportamento, para atuar de forma eficiente para atendê-los.

\subsection{Processo de decisão de compra}

Para Solomon (2011), o processo decisório para uma compra pode ser definido em um processo composto por cinco etapas bem definidas em ordem de acontecimento: reconhecimento da necessidade, intensa pesquisa e investigação, definição das opções para satisfazer esse desejo, tomada de decisão entre uma das alternativas definidas e o comportamento após o ato da compra. 
Segundo Churchill e Peter (2010), cada uma das etapas pode ser definida conforme abaixo:

Reconhecimento da necessidade: ocorre quando o indivíduo identifica algo que deseja para alterar o estado atual criando esta necessidade.

Pesquisa e investigação: este indivíduo busca, através de diversas fontes, mais informações a respeito de que formas ele poderá satisfazê-la.

Avaliação das alternativas: busca balancear todas as desvantagens e vantagens de cada uma das opções para tentar identificar qual opção é a mais satisfatória.

Tomada de decisão de qual alternativa comprar: o consumidor opta pela melhor opção depois de toda esta análise e pesquisa

Comportamento após a compra: existe a real retroalimentação sobre o produto ter sido ou não a opção mais vantajosa para ele.

Para Churchill e Peter (2000), este processo não ocorre para todos os três tipos de compras que os autores destacam existir: compras extensivas, limitadas e rotineiras.

Os autores definem cada uma das compras conforme abaixo:

Compras extensivas: ocorre quando o consumidor busca um produto que vá ser mais custoso e impactante em sua vida, o processo anteriormente destacado é realizado com mais profundidade e cautela.

Compras limitadas: exigem um pouco menos da etapa de decisão onde existe um equilíbrio na pesquisa visto que é um produto importante, mas não tanto quanto a de uma extensiva.

Compras Rotineiras: exigem um esforço praticamente nulo dos consumidores que acabam por comprar o que estão habituados a comprar ou dentre as poucas opções disponíveis de fácil acesso por serem produtos mais baratos e supérfluos.

Nas lojas Free Shop podemos destacar a presença das compras limitadas e rotineiras devido a existir portfólio que é responsável por satisfazer também vontades impulsivas e rotineiras. $O$ motivo da não 
existência da compra extensiva é o limite imposto por leis vigentes de 500 dólares por pessoa reduzindo a possibilidade de haver, dentro do portfólio, produtos que venham a exigir impactos na vida ou uma pesquisa mais extensiva.

\subsection{Os diferentes perfis de consumidores}

Uma pesquisa realizada pela empresa independente de pesquisa de mercado estratégico Euromonitor International (2018) foi capaz de identificar sete tipos diferentes de consumidores varejistas: tradicionalista estável, ativista confiante, conservador com foco familiar, aventureiro inspirado, comprador destemido, calculista planejador, otimista balanceado e comprador impulsivo.

A pesquisa realizada em 2018 foi capaz de identificar cada perfil através do seu comportamento de compra, conforme abaixo:

Tradicionalista estável: são consumidores bem decididos e difíceis de serem influenciados, focam em comprar apenas o que é imprescindível e focado em economizar em cada compra.

Ativista confiante: são responsáveis perante o meio ambiente e a própria saúde. Dão muito valor para os produtos de qualidade que apresentem características sustentáveis.

Conservador familiar: evitam compras impulsivas e são cuidadosos com a forma com a qual investem seu dinheiro em produtos. Mesmo que não efetuem muitas compras apreciam a atividade de ir a busca de pesquisa de produtos.

Aventureiro inspirado: são consumidores que avaliam muito antes de investirem seu capital em produtos e estão mais dispostos a experimentarem novas marcas de maneira mais rotineira.

Comprador destemido: consumidores definidos como não planejadores de compras pensadas no médio ou longo prazo. São focados em compras para o benefício próprio e não evitam investir nestes. 
Calculista planejador: comumente são consumidores que já estão com todo o processo de compra tomado antes de ir ao local efetua-la. São consumidores definidos como leais às marcas que têm a percepção de boa qualidade sem se importar com a maior necessidade de investimento.

Otimista balanceado: podem ser definidos como consumidores que são cautelosos com seu dinheiro, mas ao mesmo tempo praticam diversas compras impulsivas para satisfazer o bem próprio e de indivíduos que ele deseje favorecer.

Comprador impulsivo: são consumidores que por mais que possuam uma cautela com seu capital acabam fazendo muitas compras impulsivas para satisfazer desejos supérfluos para o próprio benefício através de marcas que possuam qualidade e status. 


\section{Metodologia}

Este momento do trabalho busca definir qual foi o tipo de pesquisa selecionado para trazer os resultados da pesquisa.

\subsection{Tipo de pesquisa selecionado}

Este estudo optou pela utilização da pesquisa descritiva. Para Cervo e Bervian (2003), esta pesquisa busca coletar dados, analisá-los, registrá-los e correlacioná-los sem modificar os mesmos de qualquer maneira.

Zikmund (2006) defende que este método de pesquisa optado e possui o objetivo de conseguir definir, através de certas características, uma população.

\subsection{Universo e amostra}

Este estudo optou por um universo que contempla qualquer viajante que esteja desembarcando de uma viagem internacional no Aeroporto Internacional Antonio Carlos Jobim, presente no Rio de Janeiro.

A tipologia da amostragem selecionada foi a não probabilística, ou seja, que não tem como objetivo generalizar qualquer resultado que tenha fins estatísticos para uma população maior (ANDERSON; SWEENEY; WILLIAMS, 2007).

Segundo Anderson, Sweeney e Williams (2007), as amostragens não probabilísticas podem possuir as seguintes formas: Amostragem por 
acessibilidade, Amostragem de conveniência, Amostragem por julgamento, Amostragem por cotas e Amostragem sem norma.

Para esta pesquisa específica será selecionada a Amostragem não probabilística por conveniência por ser uma abordagem mais simples no qual os objetos de pesquisa são facilmente disponíveis (ANDERSON; SWEENEY; WILLIAMS, 2007).

\subsection{Coleta de dados}

Para que os dados sejam coletados, foi realizada uma pesquisa focada em apenas um determinado grupo, procurando, através principalmente da observação, uma relação entre os indivíduos denominado de Pesquisa de Campo (GIL,2008).

A pesquisa de campo do presente estudo foi realizada através de um questionário que contém apenas perguntas fechadas. Para Gil (2008), esta técnica consiste em uma investigação que contém apenas perguntas por escrito buscando coletar as opiniões individuais, sentimentos, sensações, crenças etc.

Segundo o mesmo autor, as principais vantagens podem ser consideradas: a de serem facilmente divulgadas através, atualmente, de mensagens instantâneas online atingindo um grande número de participantes, menos custos com a aplicação do questionário como um todo, possibilidade da garantia de anonimato, entre outras.

O presente estudo se utilizou do software Qualtrics para a criação e divulgação e do questionário. O mesmo foi escolhido devido à sua amigável adaptação de uso e por possibilitar, ao final da formulação das perguntas e respostas possíveis, o compartilhamento de um fácil caminho online de acesso ao questionário, impulsionando o número de objetos de pesquisa através de uma extensa massificação de divulgação utilizando-se das redes sociais e plataformas de troca de mensagens instantâneas. 
O questionário(Anexo 1) preparado para esta pesquisa foi segmentado em três diferentes partes bem definidas com o objetivo de facilitar, posteriormente, a análise dos dados coletados.

Inicialmente as perguntas tiveram como propósito definir o perfil de cada sujeito de pesquisa através de questionamentos demográficos como: idade, renda, estado civil e número de dependentes.

$\mathrm{Na}$ segunda etapa do questionário, as perguntas tiveram como finalidade a identificação de hábitos que os respondentes possuem durante a realização de viagens.

Por último, a pesquisa de campo teve como objetivo obter dados sobre padrão de consumo em lojas de Duty Free.

\subsection{Tratamento dos dados}

Os dados foram tratados de maneira quantitativa. Através da utilização de tabelas simples e cruzadas foi possível, através das respostas obtidas do questionário online, buscar os resultados com uma comparação de frequência entre as respostas disponíveis.

\subsection{Limitações do método}

As limitações do método são exatamente os limitantes de um questionário visto o mesmo ter sido a única fonte de coleta de dados. Para Gil (1999), este método apresenta diversos pontos negativos como: a incapacidade de prestar auxílio em caso do não perfeito entendimento do que está sendo perguntado, a não garantia de que o mesmo está sendo preenchido com informações verídicas do objeto de pesquisa e principalmente o fato de cada aspecto poder ter um significado distinto para os respondentes do questionário. 


\section{Análise dos resultados}

\subsection{Perfil da amostra}

O questionário online divulgado através do site Qualtrics, conforme antes detalhado, obteve 104 respostas, mas onde não foram utilizadas as 100 para cada análise.

Através do Quadro 1, podemos notar a maioria feminina de 53 respostas $(54,08 \%)$ e a minoria Masculina com 45 respostas (45,92\%). Em relação à idade, a faixa predominante foi a de 20 a 24 anos com 57 das respostas representando (57\%) seguido pela faixa de 25 a 29 anos apresentando 22 respostas (22\%); A faixa de renda própria que teve o maior número de respostas foi a de 3 a 6 salários mínimos (de $R \$ 2.994,01$ a $\mathrm{R} \$ 5.998,00$ ) com $26 \%$ seguido pelos $24 \%$ da faixa de 1 a 3 salários mínimos ( $R \$ 998,01$ até $R \$ 2994,00)$, importante também destacar a terceira maior faixa de renda representada por $19 \%$ dos respondentes que é a de mais de 15 salários mínimos ( mais de $\mathrm{R} \$ 14970,01$ ).

Em relação ao Estado civil, tivemos uma ampla maioria de $77 \%$ de solteiros seguidos por $21 \%$ de casados.

\begin{tabular}{|c|c|c|c|c|c|c|}
\hline \multirow{2}{*}{ Sexo } & Masculino & Feminino & \multirow{2}{*}{$\begin{array}{c}\text { Estado } \\
\text { Civil }\end{array}$} & Solteiro & Casado & Outros \\
\hline & $45 \%$ & $53 \%$ & & $77 \%$ & $21 \%$ & $1 \%$ \\
\hline Idade & 20 a 24 anos & 25 a 29 & 30 a 34 & 35 a 39 & 40 a 44 & 45 ou mais \\
\hline
\end{tabular}




\begin{tabular}{|c|c|c|c|c|c|c|}
\hline \multirow{2}{*}{} & & anos & anos & anos & anos & anos \\
\cline { 2 - 7 } & $57 \%$ & $22 \%$ & $2 \%$ & $0 \%$ & $2 \%$ & $17 \%$ \\
\hline
\end{tabular}

Quadro 1: Perfil demográfico

Fonte: Elaboração autoral

Após estas perguntas demográficas iniciais, foram desenvolvidos questionamentos já voltados para identificar um perfil em relação à comportamentos de viagem como: Frequência de voos internacionais, destino procurado e principalmente em qual classe de avião o respondente costuma viaja.

Como podemos observar no Quadro 2, tivemos uma maioria de respostas de pessoas que viajam uma vez por ano com $34 \%$ seguidos por uma vez a cada dois anos e duas vezes por ano com $23 \%$ e $19 \%$ respectivamente. Os continentes mais procurados para a realização destas viagens foram Europa (38\%), América do Norte (30\%) e América do Sul com $21 \%$. Por fim os viajantes apresentaram uma grande preferência em viajar de classe econômica com $82 \%$ contra os $19 \%$ que optaram pela Executiva.

\begin{tabular}{|c|c|c|c|c|c|c|}
\hline \multirow{2}{*}{\multicolumn{5}{|c|}{ Classe Econômica }} & Executiva & Econômica \\
\hline & & & & & $18 \%$ & $82 \%$ \\
\hline \multirow{2}{*}{$\begin{array}{l}\text { Frequência } \\
\text { Viagens }\end{array}$} & 1 por Ano & $\begin{array}{l}2 \text { por } \\
\text { ano }\end{array}$ & $\begin{array}{c}3 \text { ou mais } \\
\text { por ano }\end{array}$ & $\begin{array}{c}1 \text { a cada } \\
\text { dois anos }\end{array}$ & $\begin{array}{l}1 \text { a cada } \\
\text { três anos }\end{array}$ & $\begin{array}{r}\text { Menos de } 1 \\
\text { a cada três anos }\end{array}$ \\
\hline & $34 \%$ & $19 \%$ & $9 \%$ & $23 \%$ & $7 \%$ & $8 \%$ \\
\hline \multirow{2}{*}{ Destino } & Europa & África & Ásia & Oceania & $\begin{array}{l}\text { América } \\
\text { do Norte }\end{array}$ & $\begin{array}{l}\text { América do } \\
\text { Sul }\end{array}$ \\
\hline & $\%{ }^{38}$ & $\%$ & $6 \%$ & $2 \%$ & $\%$ & $21 \%$ \\
\hline
\end{tabular}

Quadro 2: Viagens internacionais Fonte: Elaboração autoral

\subsection{Resultados}

Após toda a sessão que foi destinada a identificar o perfil da amostra, vieram as perguntas que serão responsáveis por tentar identificar uma possível relação entre a classe de avião optada em uma viagem internacional com o seu consumo na loja de Duty Free de Desembarque no Rio de Janeiro. 
Por isso, toda a análise será baseada na comparação entre estas duas classes com as respostas sobre a compra no Duty Free através de tabelas cruzadas.

O primeiro aspecto de consumo analisado foi o de gasto médio na loja de desembarque e podemos observar, através do quadro 3 , que os passageiros de classe executiva costumam gastar, em média, valores muito maiores que os de classe econômica em cada desembarque internacional apresentando $78 \%$ de valor de consumo acima dos US $\$ 200,01(R \$ 812,04)$ enquanto que os consumidores que viajam de classe econômica apresentaram $77 \%$ de gastos médios de até US $\$ 200,00(R \$ 808,00)$. Esta diferença significativa pode ser justificada pela grande diferença de renda mensal própria, indicado através do quadro 4 , entre os consumidores de cada classe onde a classe executiva apresenta um perfil onde $79 \%$ afirma ter uma renda mensal de $R \$ 8.982,01$ enquanto que o perfil dos viajantes de classe econômica apontou, com $70 \%$ das repostas, uma renda média mensal abaixo de $\mathrm{R} \$ 5988,00$.

\begin{tabular}{|c|c|c|c|}
\hline & \multicolumn{2}{|c|}{$\begin{array}{c}\text { Em qual Classe de Avião você } \\
\text { costuma viajar: }\end{array}$} \\
\hline & & Econômica & Executiva \\
\hline \multirow{8}{*}{$\begin{array}{l}\text { Quanto voce gasta, } \\
\text { normalmente, no } \\
\text { Free Shop ao } \\
\text { desembarcar no } \\
\text { aeroporto? }\end{array}$} & $\begin{array}{c}\text { Até US\$100(Até R\$ } \\
404,00)\end{array}$ & $39(49 \%)$ & $1(6 \%)$ \\
\hline & $\begin{array}{c}\text { De US\$101 a US\$200 } \\
\text { (De } R \$ 408,05 \text { a } \\
R \$ 808,00)\end{array}$ & $22(28 \%)$ & $3(17 \%)$ \\
\hline & $\begin{array}{c}\text { De US\$201 a US\$300 } \\
(\mathrm{De} R \$ 812,04 \mathrm{a} \\
\mathrm{R} \$ 1212,00)\end{array}$ & $8(10 \%)$ & $5(28 \%)$ \\
\hline & $\begin{array}{c}\text { De US } \$ 301 \text { a US } \$ 400 \\
\text { (De } R \$ 1216,04 \text { a } \\
R \$ 1616,00)\end{array}$ & $1(1 \%)$ & $1(6 \%)$ \\
\hline & $\begin{array}{c}\text { De US } \$ 401 \text { a US } \$ 500 \\
\text { (De } R \$ 1620,00 \text { a } R \$ \\
2020,00)\end{array}$ & $5(6 \%)$ & $2(11 \%)$ \\
\hline & $\begin{array}{c}\text { Mais de US\$500 (Mais } \\
\text { de R } \$ 2020,00)\end{array}$ & $0(0 \%)$ & $6(33 \%)$ \\
\hline & Não Gasto & $5(6 \%)$ & $0(0 \%)$ \\
\hline & Total & 80 & 18 \\
\hline
\end{tabular}

Quadro 3: Gasto médio no Duty Free Fonte: Elaboração autoral 


\begin{tabular}{|c|c|c|c|}
\hline & & \multicolumn{2}{|c|}{$\begin{array}{l}\text { Em qual Classe de Avião } \\
\text { você costuma viajar: }\end{array}$} \\
\hline & & Econômica & Executiva \\
\hline \multirow{8}{*}{$\begin{array}{c}\text { Qual a sua renda } \\
\text { mensal, } \\
\text { aproximadamente? } \\
\text { (Marque apenas } \\
\text { uma resposta) }\end{array}$} & Nenhuma renda. & $8(10 \%)$ & $0(0 \%)$ \\
\hline & $\begin{array}{l}\text { Até } 1 \text { salário mínimo (até } \mathbf{R} \$ \\
998,00 \text { ). }\end{array}$ & $1(1 \%)$ & $0(0 \%)$ \\
\hline & $\begin{array}{l}\text { De } 1 \text { a } 3 \text { salários mínimos (de } \\
R \$ 998,01 \text { até } R \$ 2.994,00 \text { ). }\end{array}$ & $22(27 \%)$ & $2(11 \%)$ \\
\hline & $\begin{array}{l}\text { De } 3 \text { a } 6 \text { salários mínimos (de } \\
R \$ 2.994,01 \text { até } R \$ 5.988,00 \text { ). }\end{array}$ & $26(32 \%)$ & $0(0 \%)$ \\
\hline & $\begin{array}{l}\text { De } 6 \text { a } 9 \text { salários mínimos (de } \\
R \$ 5,988,01 \text { até } R \$ 8.982,00 \text { ). }\end{array}$ & $6(7 \%)$ & $2(11 \%)$ \\
\hline & $\begin{array}{l}\text { De } 9 \text { a } 12 \text { salários mínimos (de } \\
R \$ 8.982,01 \text { até } R \$ 11.976,00) \text {. }\end{array}$ & $3(4 \%)$ & $3(16 \%)$ \\
\hline & $\begin{array}{l}\text { De } 12 \text { a } 15 \text { salários mínimos } \\
\text { (de } R \$ 11.976,01 \text { até } R \$ \\
14.970,00) \text {. }\end{array}$ & $6(7 \%)$ & $3(16 \%)$ \\
\hline & $\begin{array}{l}\text { Mais de } 15 \text { salários mínimos } \\
\text { (mais de } R \$ 14.970,01 \text { ). }\end{array}$ & $10(12 \%)$ & $9(47 \%)$ \\
\hline & Total & 82 & 19 \\
\hline
\end{tabular}

Quadro 4: Relação renda mensal com classe Fonte: Elaboração autoral

O segundo aspecto que podemos analisar é o de qual categoria os produtos são mais comprados entre os diferentes viajantes.

Como podemos notar através do quadro 5, a diferença entre o tipo de classe optado pelo viajante interfere significativamente na classe do produto que o mesmo compra. 
Podemos destacar uma muito maior preferência pela compra de produtos de categorias com tickets médios mais elevados se comparados a outras por parte da classe executiva. Isto é comprovado pela compra por parte de 50\% na categoria de eletrônicos, 39\% na categoria de óculos de sol e 39\%na categoria de relógios que possuem produtos mais caros que as outras categorias presentes na loja.

Em relação à classe econômica, podemos ressaltar a maior compra significativa de produtos da categoria comestíveis, com $71 \%$ dos viajantes, que pode ser justificada pela maior presença de promoções no ponto de venda e preços bem mais acessíveis e com maior percepção de vantagem se comparado ao mercado local.

As categorias de perfume, cosméticos e bebidas alcóolicas apresentaram comportamentos parecidos entre as classes. Oque justifica o fato de serem as três categorias mais compradas no Duty Free no Desembarque por serem de comum importância para todos os viajantes de uma aeronave.

\begin{tabular}{|c|c|c|c|}
\hline & \multicolumn{2}{|c|}{$\begin{array}{l}\text { Em qual Classe de Avião você costuma } \\
\text { viajar: }\end{array}$} \\
\hline & & Econômica & Executiva \\
\hline \multirow{8}{*}{$\begin{array}{l}\text { O que costuma } \\
\text { comprar no Free } \\
\text { Shop?(Marque } \\
\text { quantas opções } \\
\text { achar necessário) }\end{array}$} & Eletrônicos & $11(14 \%)$ & $9(50 \%)$ \\
\hline & Roupas & $2(4 \%)$ & $2(11 \%)$ \\
\hline & Óculos de Sol & $2(4 \%)$ & $7(39 \%)$ \\
\hline & Relógios & $1(1 \%)$ & $7(39 \%)$ \\
\hline & Perfume & $38(49 \%)$ & $12(67 \%)$ \\
\hline & Cosméticos & $25(32 \%)$ & $7(39 \%)$ \\
\hline & Bebidas Alcóolicas & $42(54 \%)$ & $14(78 \%)$ \\
\hline & Comidas & $55(71 \%)$ & $7(39 \%)$ \\
\hline & Total & 78 & 18 \\
\hline
\end{tabular}

Quadro 5: Relação categoria do produto comprado com as classes Fonte: Elaboração autoral 
Os viajantes também foram questionados quanto à forma de pagamento utilizado para o processamento de suas compras e, para continuar analisando o objetivo do estudo, foram comparados entre as classes como pode ser observado no quadro 6.

Como pode ser notada, a distinção entre as classes econômica e executiva não exerce uma expressiva diferença entre os padrões de consumo com ambas utilizando $O$ cartão de crédito na grande maioria das vezes.

\begin{tabular}{|c|l|c|c|}
\cline { 3 - 4 } \multicolumn{2}{c|}{} & \multicolumn{2}{c|}{$\begin{array}{c}\text { Em qual Classe de Avião você } \\
\text { costuma viajar: }\end{array}$} \\
\cline { 3 - 4 } & Econômica & Executiva \\
\hline \multirow{4}{*}{$\begin{array}{c}\text { Qual a forma de } \\
\text { pagamento que você } \\
\text { usa, normalmente, no } \\
\text { Free Shop? }\end{array}$} & Cartão de crédito & $43(54 \%)$ & $12(67 \%)$ \\
\cline { 2 - 4 } & Cartão de débito & $5(6 \%)$ & $2(11 \%)$ \\
\cline { 2 - 4 } & Dinheiro & $31(39 \%)$ & $4(22 \%)$ \\
\cline { 2 - 4 } & Outros & $0(0 \%)$ & $0(0 \%)$ \\
\hline
\end{tabular}

Quadro 6: Relação método de pagamento com as classes Fonte: Elaboração autoral

Com a finalidade de entender a perspectiva de cada consumidor perante 0 ato da compra no Duty Free e suas motivações, esta parte do questionário se utilizou da escala Likert para entender o grau de satisfação em todas as restantes perguntas.

O questionamento inicial foi voltado para o consumidor avaliar se 0 ato de comprar nestas lojas é satisfatório ou não para o mesmo. 
Conforme Quadro 7, podemos destacar um posicionamento favorável por ambos consumidores de diferentes classes. Porém, a classe executiva apresenta sua maioria, representada por $50 \%$, concordando completamente com a afirmativa de que a experiência é agradável para os mesmos. Enquanto que a classe econômica apresenta uma posição um pouco menos favorável com $45 \%$ concordando em parte com a mesma afirmativa.

\begin{tabular}{|c|c|c|c|}
\cline { 3 - 4 } \multicolumn{2}{|c|}{} & \multicolumn{2}{c|}{$\begin{array}{c}\text { Em qual Classe de Avião você } \\
\text { costuma viajar: }\end{array}$} \\
\cline { 3 - 4 } & & Econômica & Executiva \\
\hline \multirow{4}{*}{$\begin{array}{c}\text { Gosto de } \\
\text { comprar no } \\
\text { Free Shop. }\end{array}$} & $\begin{array}{c}\text { Discordo } \\
\text { totalmente }\end{array}$ & $1(1 \%)$ & $0(0 \%)$ \\
\cline { 2 - 4 } & $\begin{array}{c}\text { Discordo em } \\
\text { parte }\end{array}$ & $5(6 \%)$ & $0(0 \%)$ \\
\cline { 2 - 4 } & $\begin{array}{c}\text { Nem discordo, } \\
\text { nem concordo }\end{array}$ & $21(26 \%)$ & $2(11 \%)$ \\
\cline { 2 - 4 } & $\begin{array}{c}\text { Concordo em } \\
\text { parte }\end{array}$ & $36(45 \%)$ & $7(39 \%)$ \\
\cline { 2 - 4 } & $\begin{array}{c}\text { Concordo } \\
\text { totalmente }\end{array}$ & $17(21 \%)$ & $9(50 \%)$ \\
\hline & Total & 80 & 18 \\
\hline
\end{tabular}

Quadro 7: Avaliação sobre o ato da compra entre as classes Fonte: Elaboração autoral

Sendo mais específica, a pergunta título do quadro 8 abaixo questiona a cerca da razão do viajante realizar a compra se basear no fato de uma percepção de que os produtos disponíveis apresentam um custo benefício adequado. 
O resultado demonstra um posicionamento muito semelhante entre as classes executiva e econômica. A maioria de ambas, com mais de $50 \%$ das respostas, se situam como concordam em parte com a afirmativa.

A mesma colocação pelas duas classes comprova que a loja Free Shop ainda emite esta imagem de disponibilizar um portfólio com preços que o consumidor acredita que eles valham.

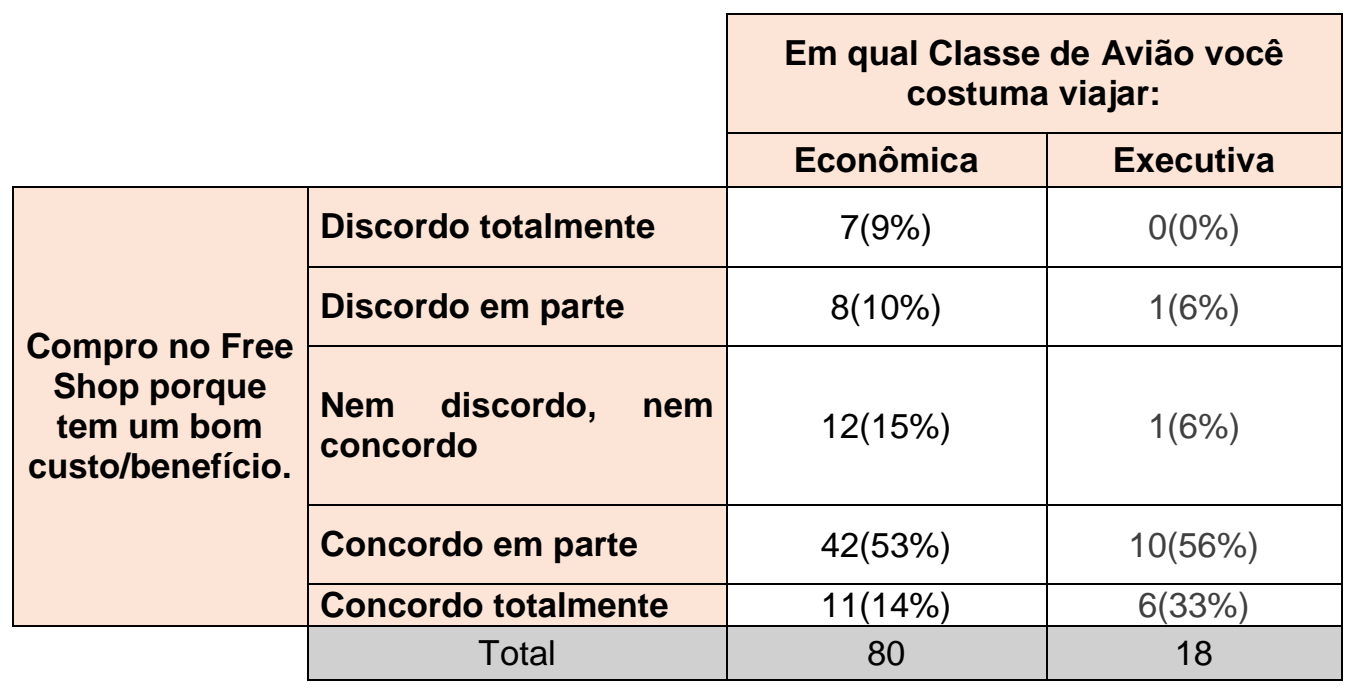

Quadro 8: Avaliação sobre o ato da compra a ser realizada por o Free Shop apresentar um bom custo benefício entre as classes

Fonte: Elaboração autoral

Ao serem questionados sobre o ambiente ser agradável e a loja oferecer um portfólio exclusivo ao se comparar ao mercado local, os dois tipos de viajantes de diferentes classes forneceram colocações que assemelharam muito.

Observando o cenário de 0 ambiente ser agradável impactar diretamente no ato de adquirir um produto nas lojas de Free Shop, ambos os 
viajantes consumidores apresentaram, com suas maiorias, um posicionamento positivo quanto ao ambiente como podemos observar no quadro 9.

Enquanto que a classe executiva demonstrou um posicionamento ainda mais favorável ao afirmar, com $44 \%$ das respostas, que concordam totalmente com a afirmativa. Verifica-se que s consumidores que fazem parte da classe econômica concordaram em parte com $41 \%$ de suas respostas que o ambiente influencia de maneira acentuada no seu desejo de compra.

Pode-se afirmar que, em relação ao portfólio exclusivo influenciar na vontade de compra, os consumidores, como podemos notar no quadro 10 , apresentaram uma paridade ainda mais destacada com as maiorias de respostas da classe executiva e econômica se posicionando com concordar em parte com esta assertiva através de 39\% e 33\% respectivamente. Esta percepção positiva vai de encontro com todo o investimento que é feito por parte da Dufry em desenvolver produtos cada vez mais exclusivos e únicos.

\begin{tabular}{|c|c|c|c|}
\hline & & \multicolumn{2}{|c|}{$\begin{array}{l}\text { Em qual Classe de Avião você } \\
\text { costuma viajar: }\end{array}$} \\
\hline & & Econômica & Executiva \\
\hline \multirow{5}{*}{$\begin{array}{l}\text { Compro no Free } \\
\text { Shop porque o } \\
\text { ambiente é } \\
\text { agradável. }\end{array}$} & Discordo totalmente & $4(5 \%)$ & $0(0 \%)$ \\
\hline & Discordo em parte & $4(5 \%)$ & $1(6 \%)$ \\
\hline & $\begin{array}{l}\text { Nem discordo, nem } \\
\text { concordo }\end{array}$ & $24(30 \%)$ & $2(11 \%)$ \\
\hline & Concordo em parte & $33(41 \%)$ & $7(39 \%)$ \\
\hline & $\begin{array}{l}\text { Concordo } \\
\text { totalmente }\end{array}$ & $15(19 \%)$ & $8(44 \%)$ \\
\hline & Total & 80 & 18 \\
\hline
\end{tabular}

Quatro 9: Avaliação sobre o ato da compra ser realizada por o Free Shop apresentar um ambiente agradável entre as classes

Fonte: Elaboração autoral

\begin{tabular}{|c|c|}
\hline \multicolumn{2}{|c|}{$\begin{array}{c}\text { Em qual Classe de Avião } \\
\text { você costuma viajar: }\end{array}$} \\
\hline Econômica & $\begin{array}{c}\text { Execut } \\
\text { iva }\end{array}$ \\
\end{tabular}




\begin{tabular}{|c|c|c|c|}
\hline \multirow{5}{*}{$\begin{array}{l}\text { Compro no } \\
\text { Free Shop } \\
\text { porque possui } \\
\text { um portfólio } \\
\text { exclusivo que } \\
\text { não encontro } \\
\text { no mercado } \\
\text { local. }\end{array}$} & \begin{tabular}{|l|}
$\begin{array}{l}\text { Discordo } \\
\text { totalmente }\end{array}$ \\
\end{tabular} & $7(9 \%)$ & $0(0 \%)$ \\
\hline & Discordo em parte & $13(16 \%)$ & $1(6 \%)$ \\
\hline & $\begin{array}{l}\text { Nem discordo, nem } \\
\text { concordo }\end{array}$ & $16(20 \%)$ & $4(22 \%)$ \\
\hline & Concordo em parte & $28(35 \%)$ & $7(39 \%)$ \\
\hline & \begin{tabular}{|l|}
$\begin{array}{l}\text { Concordo } \\
\text { totalmente }\end{array}$ \\
\end{tabular} & $16(20 \%)$ & $6(33 \%)$ \\
\hline & Total & 80 & 18 \\
\hline
\end{tabular}

Quadro 10: Avaliação sobre o ato da compra ser realizada por o Free Shop apresentar um portfólio exclusivo entre as classes Fonte: Elaboração autoral

Através da penúltima pergunta realizada no questionário, podemos observar a percepção dos consumidores acerca do atendimento físico das lojas ser responsável ou não por influenciar na compra.

A classe econômica afirmou, com sua maioria de $43 \%$, que 0 atendimento é indiferente quanto a sua realização de compra. Diferentemente da classe executiva que apresentou, com sua maioria de $33 \%$ das respostas, considerar 0 atendimento sendo algo diferencial que acarreta em positivamente auxilia-los nas compras.

A acentuada distinção percebida no Quadro 11 pode ser justificada pelo fato da classe executiva procurar produtos de categorias com tickets maiores que apresentam vendedores mais direcionados que dão todo o suporte necessário para esta tomada de decisão. Isto não está presente nas categorias mais procuradas pela classe econômicas que não exige muito suporte para a tomada de decisão por serem produtos mais conhecidos e com pouca distinção técnica para seus concorrentes próximos.

\begin{tabular}{|c|l|c|c|}
\cline { 3 - 4 } \multicolumn{2}{c|}{} & \multicolumn{2}{|c|}{$\begin{array}{c}\text { Em qual Classe de Avião você } \\
\text { costuma viajar: }\end{array}$} \\
\cline { 2 - 4 } \multicolumn{2}{c|}{} & Econômica & Executiva \\
\hline $\begin{array}{c}\text { Compro no Free } \\
\text { Shop porque o } \\
\text { atendimento é } \\
\text { bom. }\end{array}$ & $\begin{array}{l}\text { Discordo } \\
\text { totalmente }\end{array}$ & $7(9 \%)$ & $0(0 \%)$ \\
\cline { 2 - 4 } & Discordo em parte & $10(13 \%)$ & $5(28 \%)$ \\
\hline
\end{tabular}




\begin{tabular}{|l|c|c|c|}
\hline $\begin{array}{l}\text { Nem discordo, } \\
\text { nem concordo }\end{array}$ & $34(43 \%)$ & $3(17 \%)$ \\
\hline Concordo em parte & $14(18 \%)$ & $4(22 \%)$ \\
\hline $\begin{array}{l}\text { Concordo } \\
\text { totalmente }\end{array}$ & $14(18 \%)$ & $6(33 \%)$ \\
\hline Total & 79 & 18 \\
\hline
\end{tabular}

Quadro 11: Avaliação sobre o ato da compra ser realizada por o Free Shop apresentar um bom atendimento entre as classes

Fonte: Elaboração autoral

Por fim os consumidores foram questionados sobre a afirmação de serem levados a efetuar a compra devido ao Free Shop providenciar uma experiência única.

Os compradores de classe econômica com $30 \%$ das repostas se posicionaram como indiferentes quanto a este aspecto. Já a classe executiva, com sua maioria, apresentou um posicionamento de que percebem uma experiência única favorável em influenciar na sua vontade e ato de compra.

\begin{tabular}{|c|c|c|c|}
\hline & & \multicolumn{2}{|c|}{$\begin{array}{c}\text { Em qual Classe de Avião você } \\
\text { costuma viajar: }\end{array}$} \\
\hline & & Econômica & Executiva \\
\hline \multirow{6}{*}{$\begin{array}{c}\text { Compro no } \\
\text { Free Shop } \\
\text { porque é } \\
\text { uma } \\
\text { experiência } \\
\text { diferente. }\end{array}$} & \begin{tabular}{|l|} 
Discordo \\
totalmente
\end{tabular} & $19(24 \%)$ & $1(6 \%)$ \\
\hline & Discordo em parte & $8(10 \%)$ & $2(11 \%)$ \\
\hline & $\begin{array}{l}\text { Nem discordo, nem } \\
\text { concordo }\end{array}$ & $24(30 \%)$ & $4(22 \%)$ \\
\hline & Concordo em parte & $22(28 \%)$ & $5(28 \%)$ \\
\hline & \begin{tabular}{|l|} 
Concordo \\
totalmente
\end{tabular} & $7(9 \%)$ & $6(33 \%)$ \\
\hline & Total & 80 & 18 \\
\hline
\end{tabular}

Quadro 12: Avaliação sobre o ato da compra ser realizada por o Free Shop apresentar uma experiência diferente entre as classes

Fonte: Elaboração autoral 


\section{Considerações finais}

Este trabalho procurou identificar uma relação direta entre a classe de voo optada pelo viajante e seu comportamento de consumo nas lojas Free Shop. Pode-se afirmar que este estudo será de grande relevância para 0 entendimento deste segmento específico de consumidor.

Com o objetivo de propor uma análise mais aprofundada, foi abordada uma base teórica extensiva acerca do tema de comportamento do consumidor e suas motivações e desejos de compras que permitiu relacionar todos estes conceitos apresentados com os resultados obtidos do questionário criado obtendo uma correta análise.

A análise dos resultados foi capaz de concluir que o comportamento do consumidor de uma classe de voo econômica é bastante diferenciado de um consumidor que costuma viajar de classe executiva. 
Podem-se destacar principalmente as maiores disparidades entre estes dois tipos de consumidores que são: o ticket médio de gastos em cada compra, a procura por categorias mais exclusivas por parte da classe executiva, distinta percepção acerca dos atendimentos impactando em suas compras e a percepção de uma experiência única.

Todas estas diferenças acima foram notadas de forma que a classe executiva providenciou um posicionamento sempre mais favorável quanto às afirmativas colocadas determinando ser um consumidor mais exigente e impactado por diversos outros fatores além dos produtos.

Percebe-se que a diferença de gastos não interfere no meio de pagamento optado por nenhuma das classes e que as duas se posicionaram favoráveis quanto ao custo benefício dos produtos e sua contentação com consumir neste tipo de varejo.

Em razão de a pesquisa ter sido limitada a apenas passageiros que desembarcaram no Aeroporto Internacional do Rio de Janeiro, pode se afirmar que existem ainda muitos outros aspectos e características a serem investigados para colher dados e se aprofundar ainda mais no reconhecimento deste tipo de consumidor e o impacto das classes de voo nos mesmos. 


\section{Referências Bibliográficas}

2018 Survey Results: Using Consumer Types to Understand the Path to Purchase Euromonitor International. Disponível em:

$<$ https://go.euromonitor.com/white-paper-survey-2018-survey-consumertypes.html> Acesso em: 15 abr. 2019.

ANDERSON, D. R.; SWEENEY, D. J.; WILLIAMS, T. A. Estatística aplicada à administração e economia. 2. ed. São Paulo: Editora Cengage Learning, 2007.

BRASIL. Dados e estatísticas. Aeroportos. Agência Nacional de Aviação Civil. Disponível em: <https://www.anac.gov.br/assuntos/dados-eestatisticas/aeroportos>. Acesso em: 15 abr. 2019.

CERVO, Amado L.; BERVIAN, Pedro A. Metodologia científica. São Paulo: Pearson, 2003.

CHIAVENATO, Idalberto. Introdução à teoria geral da administração. 9. ed. São Paulo: Manole, 2014. 
CHURCHILL Jr., Gilbert A., PETER, J. Paul. Marketing: criando valor para o cliente. São Paulo: Saraiva, 2000.

Saraiva, 2012.

Marketing: criando valor para os clientes. 3 ed. São Paulo:

GIL, Antonio Carlos. Como elaborar projetos de pesquisa. 4. ed. São Paulo: Atlas, 2008.

KOTLER, Philip. Administração de Marketing. 4ํa ed. São Paulo: Atlas, 1996.

Hall, 2006.

; KELLER, K. Administração de Marketing. São Paulo: Prentice

; KELLER, Kevin Lane. Administração de Marketing. 12. ed. São Paulo: Pearson Prentice Hall, 2006.

MASLOW, Abraham H. A Theory of Human Motivation. Eastford: Martino Fine Books, 1943.

Números do aeroporto. Rio Galeão. Disponível em:

<http://www.riogaleao.com/institucional/numeros-do-aeroporto/>. Acesso em: Acesso em: 15 abr. 2019.

SOLOMON, Michael. O comportamento do consumidor. Porto Alegre:

Bookman, 2008.

O comportamento do Consumidor: comprando, possuindo e sendo. 11. ed. Porto Alegre: Bookman, 2016.

ZIKMUND, William G. Princípios da pesquisa de marketing. 2a. ed. São

Paulo: Thomson, 2006. 
7 Apêndice - Questionário aplicado aos consumidores do Free Shop

1. Sexo:

a. Feminino

b. Masculino

2. Idade: anos

3.Qual a sua renda mensal, aproximadamente? (Marque apenas uma resposta)

a. Nenhuma renda.

b. Até 1 salário mínimo (até $R \$ 998,00$ ).

c. De 1 a 3 salários mínimos (de $R \$ 998,01$ até $R \$ 2.994,00$ ).

d. De 3 a 6 salários mínimos (de $R \$ 2.994,01$ até $R \$ 5.988,00$ ).

e. De 6 a 9 salários mínimos (de $R \$ 5,988,01$ até $R \$ 8.982,00$ ).

f. De 9 a 12 salários mínimos (de $R \$ 8.982,01$ até $R \$ 11.976,00$ ).

g. De 12 a 15 salários mínimos (de $R \$ 11.976,01$ até $R \$ 14.970,00$ ).

h. Mais de 15 salários mínimos (mais de $R \$ 14.970,01$ ).

4. Estado civil:

a. Solteiro 

b. Casado
c. Divorciado/separado
d. Viúvo
e. Outros

5. Indique o número de viagens internacionais que você costuma fazer:
a. 1 por ano
b. 2 por ano
c. 3 por ano
d. 1 a cada dois anos
e. 1 a cada três anos
f. Menos de 1 a cada 3 anos

6. Com quem costuma viajar: (Marque quantas opções achar necessário)
a. Filhos
b. Pais
c. Avós
d. Amigos
e. Marido/Mulher
f. Namorado (a)
g. Outros

7. Destino para o qual costumar viajar (Pode marcar mais de um)
a. América do Sul
b. Ásia (sem contar o Oriente Médio)
c. Oriente Médio
d. América do Norte
e. Oceania
f. África

8. Em qual Classe de Avião você costuma viajar:
A. Econômica
B. Executiva

Em relação ao Free Shop no desembarque do aeroporto Antônio Carlos Jobim, responda as perguntas a seguir:

09. Quanto você gasta, normalmente, no Free Shop ao desembarcar no aeroporto?
a. Até US\$100(Até $\mathrm{R} \$ 404,00$ )
b. De US\$101 a US\$200 (De R $\$ 408,05$ a $R \$ 808,00$ )
c. De US\$201 a US\$300 (De $R \$ 812,04$ a $R \$ 1212,00$ ) 
d. De US\$301 a US\$400 (De $R \$ 1216,04$ a $R \$ 1616,00)$

e. De US\$401 a US\$500 (De $R \$ 1620,00$ a $R \$ 2020,00$ )

f. Mais de US\$500 ( Mais de $\mathrm{R} \$ 2020,00$ )

11. O que costuma comprar no Free Shop?

a. Eletrônicos

b. Roupas

c. Óculos de Sol

d. Relógios

e. Perfume

f. Cosméticos

g. Bebidas Alcóolicas

h. Comidas

i. Outros

12. Qual a forma de pagamento que você usa, normalmente, no Free Shop?
a. Cartão de crédito
b. Cartão de débito
c. Dinheiro
d. Outros

13. Gosto de comprar no Free Shop.
a. Discordo totalmente
b. Discordo em parte
c. Nem discordo, nem concordo
d. Concordo em parte
e. Concordo totalmente

14. Compro no Free Shop porque tem um bom custo/benefício.
a. Discordo totalmente
b. Discordo em parte
c. Nem discordo, nem concordo
d. Concordo em parte
e. Concordo totalmente

15. Compro no Free Shop porque o ambiente é agradável.
a. Discordo totalmente
b. Discordo em parte
c. Nem discordo, nem concordo
d. Concordo em parte
e. Concordo totalmente

16. Compro no Free Shop porque o atendimento é bom. 

a. Discordo totalmente
b. Discordo em parte
c. Nem discordo, nem concordo
d. Concordo em parte
e. Concordo totalmente

17. Compro no Free Shop porque possui um portfólio exclusivo que não encontro no mercado local.
a. Discordo totalmente
b. Discordo em parte
c. Nem discordo, nem concordo
d. Concordo em parte
e. Concordo totalmente

18. Compro no Free Shop porque é uma experiência diferente.
a. Discordo totalmente
b. Discordo em parte
c. Nem discordo, nem concordo
d. Concordo em parte
e. Concordo totalmente 